\title{
Raquitismos refractarios a la vitamina D
}

NRES.: JAVITR TORRES-GOTTIA T. *; EDECIA OCHOA A. **; MARIA EUGENIA RADRIGAN *; ELIANA FERNANDEZ *.

Las formas clínicas de raquitismo pueden dividirse por su etiopatogenia en dos grandes grupos: carenciales y no carenciales; de acuerdo a la clasificación propuesta por nosotros en una comunicación anterior (1).

Las provocadas por falta de aporte de vitamina $\mathrm{D}$ en la dieta, o por menor irradiación solar constituyen el grupo de "carencias primarias", sensibles a la administración oral de vitamina $\mathrm{D}$ a las dosis habituales. Las que hemos llamado "carencias secundarias" pueden deberse a trastornos de la absorción intestinal o a alteraciones del metabolismo de la vitamina $\mathrm{D}$.

El metabolismo de la vitamina $D$ se realiza en dos etapas: la primera en el hígado para formar la 25 hidroxivitamina $D$ que es la que circula por la sangre y cuya formación es indispensable para la segunda etapa metabólica que se realiza en el riñón. A nivel del túbulo proximal renal se produce la segunda hidroxilación que da lugar a la síntesis de 1-25 di hidroxi vitamina $\mathrm{D},-1-25$ $(\mathrm{OH}) 2 \mathrm{D}$ - que es el principio verdaderamente activo $u$ hormona antiraquítica (2) (3).

El uso de los metabolitos activos de vitamina $\mathrm{D}$ en investigación ha permitido encontrar el factor común a una serie de formas clínicas que se describían como diferentes. Así por ejemplo se sabe que tanto la deficiencia genética de la enzima 25 hidroxivitamina D -1- hidroxilasa (4) como la alteración del túbulo proximal renal producen insuficiencia de hormona antiraquítica.

Hay otras formas no carenciales: hipo-

\footnotetext{
* Unidad de Nutrición. Departamento de Pediatría. H. Roberto del Río

** Médico Servicio de Nefrología. H. Roberto del Río y Departamento de Medicina Experimental. Area Norte. U. de Chile.
}

fosfatemia familiar y raquitismo oncogénico provocadas por fosfaturia exagerada y otros cuadros menos conocidos como la hipofosfatasia (5).

Con la profilaxis sistemática que se hace en Chile, las formas clínicas de raquitismo por carencia de vitamina $D$ han disminuido. Cuando se presentan, son generalmente de grado leve, por lo menos en las zonas central y norte del país. Las formas graves de raquitismo suelen ser provocadas por etiologías diferentes al menor aporte de vitamina $\mathrm{D}$ en la dieta o a la menor irradiación solar.

Presentamos tres casos clínicos de raquitismo grave, estudiados en el transcurso del último año en el Hospital Roberto del Río.

\section{CASOS CLINICOS}

No. 1.- Isabel S. Edad: 1 año 3 meses.

Antecedentes familiares: Padres sin antecedentes patológicos. 4 hermanos mayores vivos, 3 hombres y una mujer. 2 hermanos hombres muertos a la cdad de cinco meses y un año, por patología infecciosa. Ningún micmbro de la familia sufrió de raquitismo $\mathrm{u}$ otras afecciones que pudieran relacionarse con la enfermedad de la niña. Todos los miembros de la familia tienen calcemia y fosfemia en limites normales.

Antecedentes personales: Nació de embarazo y parto normales con 2.500 gr. de peso. El primer mes bajó a 2.400 gr. probablemente por hipogalactia materna. Desde el segundo mes, con alimentación artificial adecuada, progresó con incrementos casi normales hasta los 5 meses. De los 5 a los 8 


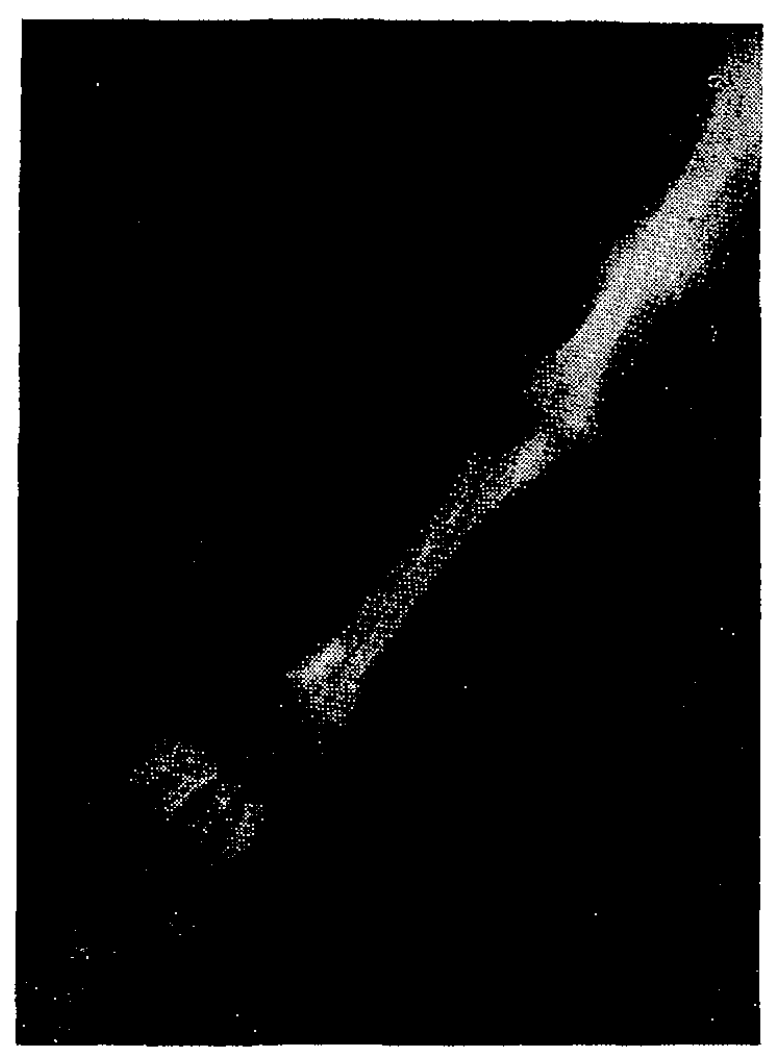

Figura 1 a.- Caso Nọ 1: Radiogralía extremidad superior al iniciar el tratamiento.

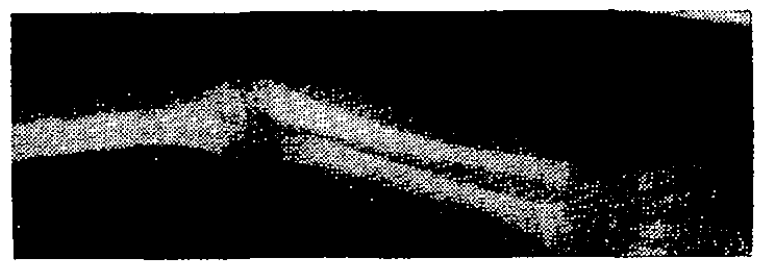

Figura 1 b.- Caso Nọ 1: radiografía despućs de 7 meses de tratamiento.

meses sus incrementos son menores a lo esperado. A los 8 meses pesa 5.600 gr. y tiene $62 \mathrm{~cm}$. de talla. A esta edad tiene su primera hospitalización con los diagnósticos de bronconeumonía y raquitismo. Curó de la bronconeumonía sin complicaciones y recibió vitamina D 600.000 unidades por vía oral. Anteriormente había recibido una dosis igual al mes de edad. Continuó con un aporte de 500 a 1.000 unidades de vitamina $\mathrm{D}$ al día en forma de gotas polivitamínicas. Desde su alta del hospital se detiene el progreso pondoestatural y se acentúan los síntomas de raquitismo, por lo que un mes después se hospitaliza en la Unidad de Nutrición.

Ex. físico: Peso: 5.770 gr. Talla: $62,4 \mathrm{~cm}$. Tronco: 39,1. Perímetro craneano $43 \mathrm{~cm}$. Relación Peso-Edad 59\%. Relación Peso-Talla
$90 \%$. Craneotabes y rosario costal pronunciados, surcos de Harrinson, frente ligeramente prominente, cnsanchamiento de epífisis a nivel de muñecas y tobillos, tibias incurvadas con concavidad hacia adelante, caderas en abducción y rotación externa, hipotonía muscular generalizada, no puede mantrarse de pie, se sienta sola. No manifiesta dolor espontánco ni provocado por los movimientos. ITo reacciona al examen. Apatía mancada.

Laboratorio: Calcemia 7.7, Fosfemia 3,1 mg. $\%$. Fosfatasa alcalina 17,3 unidades Bodanskv. Hemograma, sedimento urinario y uremia normales.

Direvactiro: Raquitismo refractario a la vitamina $\mathrm{D}$.

Eirlución: A su ingreso presentó tres intercurrencias succsivas: bronquitis, bronconeumonía enmplicada con atelectasia del lóbulo superior derecho y varicela gravc. El estudio de la causa de su raquitismo descartó carencia secundaria de vitamina $\mathrm{D}$ por malabsorción intestinal, porque no hubo esteatorrea, no tenía antecedentes de trastornos gastrointestinales y la carotinemia fue normal.

La tabla N. 1, en la primera columna, resume los principales datos de los exámenes practicados antes de iniciar su tratamiento. Los síntomas más destacados fueron: hipocalcemia, hipofosfemia, fosfatasa alcalina aumentada, hiperfosfaturia, hiperaminoaciduria y acidosis con orina alcalina. La prueba de acidificación urinaria corta con cloruro de amonio mostró persistencia de $\mathrm{pH}$ alcalino ( $\mathrm{pH}$ en orina $6,5-7,04$ ) con acidez titulable baja, cifras de amonio dentro de lo normal y bicarbonaturia elevada con concentración plasmática de bicarbonato de hasta $18,5 \mathrm{mEq}$./litro. No se determinó umbral de $\mathrm{HCO} 3$ porque no se consideró prudente aumentar su acidosis en ese momento. La radiografía de huesos mostró: "Acentuada desmineralización ósea con adelgazamiento de la cortical y atrofia trabecular. Borramiento e irregularidades de la línea de calcificación provisoria. Ensanchamiento metafisario y esbozos de espolones laterales. Finas imágenes de osteofitos periostales múltiples. Desarrollo óseo de 3 meses de edad radiológica.

Se investigó cistinosis, antecedentes de intoxicación con metales pesados, tetraciclinas o antecedentes hereditarios de Sindrome de Fanconi con resultado negativo.

Por haber recibido vitamina $D$ en dosis elevadas $\sin$ modificación de su raquitismo 
decidimos probar otra conducta terapéutica. Empezamos por corregir la acidosis con bicarbonato de sodio por vía oral. Después de 15 días iniciamos tratamiento con $400 \mathrm{mg}$. de calcio y $375 \mathrm{mg}$. de Fósforo Sandoz M.R. diarios por vía oral, más hidroclorotiazida o bicarbonato de acuerdo a las variaciones del Astrup. Después de tres meses la familia suspendió el tratamiento sin indicación médica y no volvió a control hasta un mes más tarde. Al comprobar que la evolución continuó favorable aún en el mes que estuvo sin trataraiento, no se juzgó necesario reiniciarlo de inmediato. Se administró vitamina $\mathrm{D}$ 5.000 unidades diarias por 15 dias, en nueva hospitalización y se dio de alta para control ambulatorio.

La tabla 1, muestra la evolución de los distintos signos clínicos y de laboratorio. La radiografía, después de 2 meses de tratamiento mostró: "recalcificación de la zona de calcificación provisoria a nivel de las me- táfisis, aumento del largo de las diáfisis de femur y tibia y engrosamiento del periostio". Al final del tercer mes las imágenes de raquitismo eran mínimas. Durante el mes que estuvo sin tratamiento, continuó la mejoria y finalmente, al quinto mes la imagen radiológica era casi normal. En la figura $\mathrm{N}^{\circ}$ 1 se comparan las imágenes de la primera y última radiografía.

A los 50 días de tratamiento pudo mantenerse de pie y en el último control camina nomalmente. Sus incrementos de peso y longitud fueron también satisfactorios. Durante los 3 meses de tratamiento ganó 800 gr. y creció $3 \mathrm{~cm}$. Al completar los 5 meses creció $2 \mathrm{~cm}$. más. Se consiguió un último control a los 8 meses de iniciado el tratamiento y aunque no se pudo hacer calcemia ni fosfemia, la fosfatasa alcalina seguía normal, no había acidosis y clínicamente evolucionaba satisfactoriamente con buen progreso de peso y talla.

T A B L A 1

CASO NO 1

EVOLUCION DE SIGNOS CLINICOS Y DE LABORATORIO

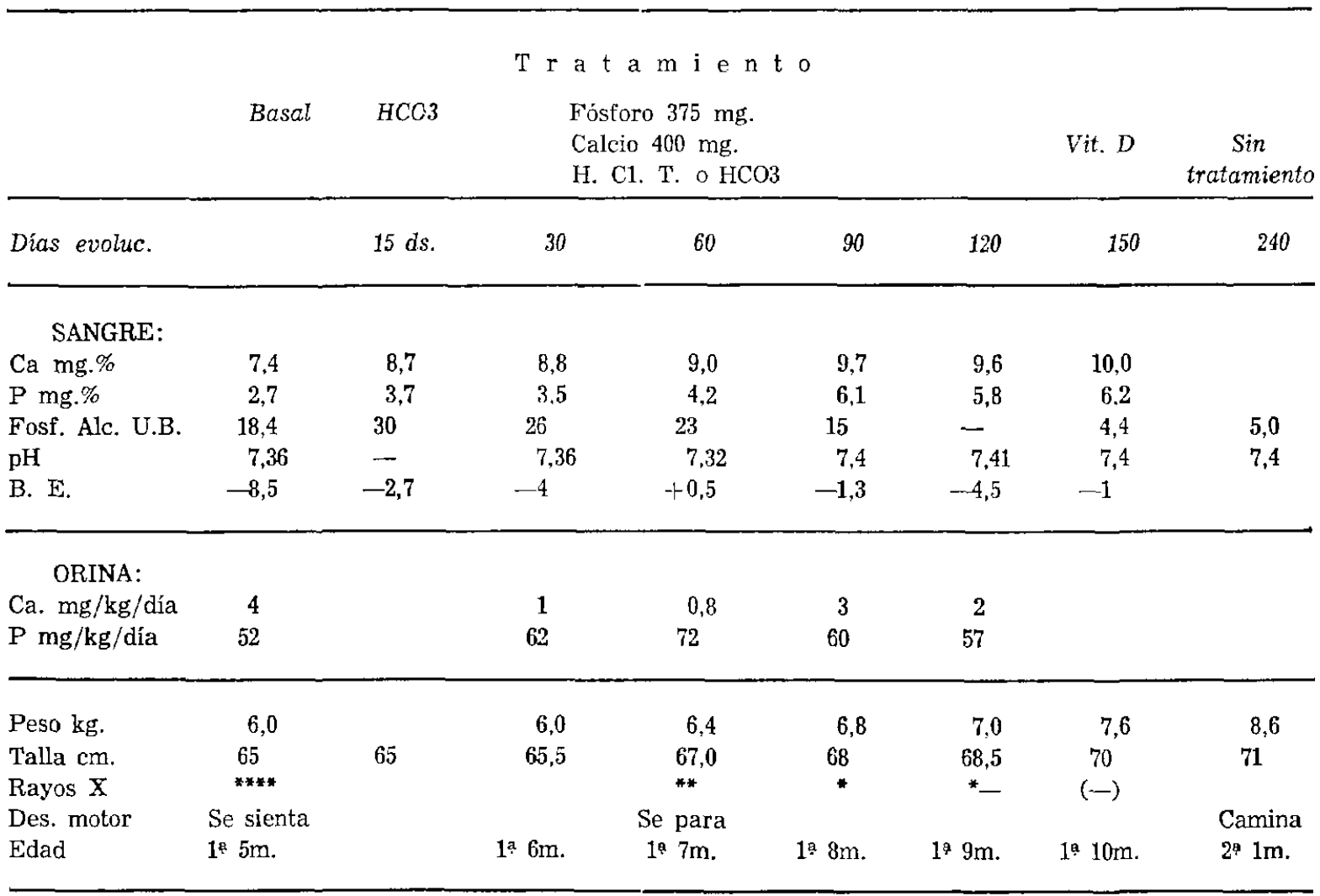


Caso No 2. Ana C. C. Edad: 2 años $8 \mathrm{~ms}$. 10 días.

Antecedentes familiares: Padres jóvenes, sanos, sin antecedentes patológicos ni afecciones óseas en ningún miembro de la familia. Tienen dos hijas, la menor de las cuales es la paci nte. No hay consanguinidad. Calcemia y Fosfemia normales en los padres y la hermana mayor.

Antecedentes personales: Nació de parto normal, de término, con peso de 3.250 gr. Sana. Bien alimentada con pecho hasta los 9 meses. Recibió golpe vitamínico con 600.000 unidades de vitamina $\mathrm{D}$, oral, a las edades de 1 mes, 7 meses, 9 meses y 11 meses. Progresó bien hasta los 2 meses (peso 5.000 gr.). De ahí adelante su curva ponderal es deficiente y llega al año con $7.210 \mathrm{gr}$. de peso (Rel. Peso-Edad 73\%). Del año a los 2 años mejora discretamente y llega a 10.000 gr. de peso (Rel. P/E. 80\%). Desde los 2 años se estacionan el peso y la talla. No tuvo otras enfermedades serias aparte del raquitismo. No sufrió de diarreas a repetición ni tiene antecedentes de sindrome de malabsorción intestinal.

Examen físico: Peso, 10.030 gr. Talla 76 $\mathrm{cm}$. Tronco $48 \mathrm{~cm}$. Perímetro craneano 47,5 $\mathrm{cm}$. Relación P/E 73\%. Rel. P/T 98\%.

Craneo de forma normal con fontanela de 1,5 por $1,5 \mathrm{~cm}$. No se aprecia craneotabes. Dentición hasta los premolares con dos incisivos caídos espontáneamente. Tórax con rosario costal marcado, clavículas anguladas. Engrosamiento de epífisis de codos, muñecas y rodillas. Dolor más marcado en extremidades inferiores que se manifiesta al levantarla o cambiarla de posición. Se sienta sola pero no se mantiene de pie. No aparenta retraso psíquico.
Laboratorio: Calcemia 9,5. Fosfemia 2,5. Fosfatasa alcalina 33,1 U. B. Acidosis con exceso de base que fluctúa alrededor de -5 . Calciuria en límites normales $3,8 \mathrm{mg}$. $/ \mathrm{kg}$.; Fosfaturia de $42 \mathrm{mg}$. $/ \mathrm{kg}$. en 24 horas. Aminoaciduria con aumento global de todos los aminoácidos. No hubo glicosuria. Radiografía con imágenes evidentes de raquitismo. $\mathrm{Ca}$ rotinemia normal: 42,8 gamas.

Diagnóstico: Raquitismo refractario a la vitamina $D$ por: 1) ¿Hipofosfatemia familiar? 2) ¿Alteración del metabolismo de la vitamina $D$ ?

Evolución: Se indicó calcio 0,5 gr. y Fósforo Sandoz M.R. $375 \mathrm{mg}$. por vía oral. Por causas involuntarias sólo recibió el fósforo durante la primera semana. Presentó decaimiento, acentuación de los dolores óseos y elevación de la fosfatasa alcalina hasta 50 U. B. Al añadirse $1 \mathrm{gr}$. de calcio diario, no se obtuvo mejoría. Continuó con dolores óseos generalizados y la calcemia y fosfemia descendieron a 8,8 y $1,9 \mathrm{mg} . \%$ respectivamente. Con estos datos se suspende el tratamiento. La prueba de acidificación corta con $\mathrm{NH}_{4} \mathrm{Cl}$ revela que el umbral de bicarbonato probable es de $13 \mathrm{mEq} /$ litro. Por debajo de este umbral acidifica bien (Tabla 2).

Teniendo en cuenta la segunda posibilidad diagnóstica de alteración del metabolismo de la vitamina D y no disponiendo de los metabolitos activos, se inicia tratamiento con 600.000 unidades diarias de vitamina $\mathrm{D}$ por 2 días y 5.000 unidades diarias después, más calcio y fósforo por vía oral. $\mathrm{Al}$ mes se aumenta la dosis a 10.000 unidades diarias por 15 días y luego a 100.000 diarias sin lograrse sino mejorías discretas y pasajeras. Después de completar un período de 3 meses de tratamiento, la niña deja de concurrir a sus controles y no reaparece hasta

T A B L A 2

CASO Ne 2

PRUEBA DE ACIDIFICACION URINARIA CORTA CON CLORURO DE AMONIO.

\begin{tabular}{|c|c|c|c|c|c|c|c|c|c|}
\hline & \multirow[b]{2}{*}{$\mathrm{pH}$} & \multicolumn{2}{|c|}{$S A N G R E$} & \multirow[b]{2}{*}{$\begin{array}{l}\text { B. E. } \\
\mathrm{meE} / 1\end{array}$} & \multirow[b]{2}{*}{$\mathrm{pH}$} & \multicolumn{2}{|c|}{$O R I N A$} & \multirow[b]{2}{*}{$\mathrm{HCO} 3$} & \multirow[b]{2}{*}{$\mathrm{H}+$} \\
\hline & & $\begin{array}{r}\mathrm{HCO} 3 \\
\mathrm{mEq} / 1\end{array}$ & $\begin{array}{r}\mathrm{CO} 2 \\
\mathrm{~mm} . \mathrm{Hg} .\end{array}$ & & & A. T. & $\mathrm{NH} 4$ & & \\
\hline \multirow{3}{*}{$\begin{array}{l}\text { Basal } \\
\text { con NH4 }\end{array}$} & 7.356 & 19,4 & 35,5 & $-4,5$ & 7,23 & 0,94 & 17,9 & 19,3 & 0,46 \\
\hline & 7.355 & 13,4 & 25,0 & $-9,8$ & 6,85 & 3,65 & 37,0 & 12,3 & 28,4 \\
\hline & & & & & 5.4 & 32,0 & 160,5 & 0,7 & 191,8 \\
\hline
\end{tabular}


2 meses después en que llega al servicio de cirugía por sospecha de fractura patológica que no se confirma. Tenía marcado dolor en extremidades inferiores. La radiografía mostró: "predominio de osteoporosis con algunas líneas de calcificación provisoria y muy discreta mejoría de las lesiones de raquitismo que sigue calificado de grave".

Se decide rehospitalizarla en la Unidad de Nutrición.

Reingresa a la edad de 3 años y 3 meses y 21 días. Peso $10.170 \mathrm{gr}$. Talla $79 \mathrm{~cm}$. Tronco, 48,8. Perímetro craneano 48,6. Relación $\mathrm{P} / \mathrm{E} 68 \%$. P/T 94\%. Fontanela anterior apenas puntiforme, se mantiene el rosario costal y el ensanchamiento de las epífisis.

Se indica vitamina $D$ por vía oral 200.000 U. y gluconato de calcio 1 gr. diarios. Los resultados del tratamiento y la evolución de los signos clínicos y de laboratorio se resumen en la tabla 3 .

A los 2 meses de tratamiento empieza a caminar, hay mejoría evidente del estado general y se normaliza la tasa de fosfatasa alcalina en sangre, al igual que la calcemia y fosfemia.

Caso No 3. Paola Z.C. Edad: 3 años 10 meses.

Antecedentes familiares: Padres jóvenes, sin consanguineidad, la madre de talla baja tiene gran deformidad de extremidades inferiores con marcha de pato. Se sabe que dos tíos y la bisabuela materna tendrían genu varo. La paciente tiene un hermano menor, de 1 año y 10 meses que aparentemente estaría iniciando igual sintomatología. El estudio realizado en la madre muestra: calcemia 9,5 y fosfemia $1,95 \mathrm{mg} . \%$. Calciuria 107 $\mathrm{mg}$./día. Fosfaturia $165 \mathrm{mg} . /$ día.

Antecedentes personales: Embarazo de 8 meses. Parto normal con peso de $2.300 \mathrm{gr}$. Controlado en consultorio periférico recibe $600.000 \mathrm{U}$. de vitamina $\mathrm{D}$ en dos oportunidades en el primer año de vida y otra dosis igual 6 meses antes del ingreso al hospital. Su desarrollo psicomotor fue normal hasta la edad de 1 año y 9 meses, cuando comenzó a caminar con marcha de pato. En esa oportunidad se toma radiografía de pelvis que descarta displasia de caderas. En los meses que siguen notan progresiva deformidad de extremidades inferiores, por angulamiento de femures y tibias, sin dolor ni alteraciones funcionales.

Examen físico: Ingresa con 3 años y 10 meses de edad. $91 \mathrm{~cm}$. de talla y $14 \mathrm{~kg}$. de peso. Tiene numerosas caries dentarias, rosario costal esbozado sin surcos de Harrison. Engrosamiento metafisario más notorio a nivel femoral. Genu varo bilateral por incurbación de fémures $\mathrm{y}$ tibias $\mathrm{y}$ rotación interna marcada. Los Rayos X muestran pelvis normal, incurvación de fémures y tibias con acentuado genu varo; irregularidad de lí-

T A B L A 3

CASO No 2

ELOCLUCION DE SIGNOS CLINICOS Y DE LABORATORIO CON TRATAMIENTO DE VITAMINA $D-200.000$ U. DIARIAS

\begin{tabular}{|c|c|c|c|c|c|c|}
\hline & er Ingreso & Día 0 & $10 \mid d s$ & $15 d s$. & $25 d s$. & $45 d s$ \\
\hline \multicolumn{7}{|l|}{ SANGRE } \\
\hline $\mathrm{Ca} \mathrm{mg} . \%$ & 9,5 & 8,5 & 9,3 & 9,2 & 9,0 & 9,3 \\
\hline P mg\% & 2,5 & 3,44 & 3,8 & 5,7 & 6,0 & 6,3 \\
\hline Fosfatasa Al. U.B. & 30,2 & - & 15,8 & - & 4,4 & \\
\hline $\mathrm{pH}$ & $7,37-7,39$ & 7,5 & 7,4 & 7,44 & 7,49 & 7,46 \\
\hline B. E. & $-4,6-4,8$ & $-3,8$ & $-3,8$ & $-6,3$ & $-6,2$ & -4 \\
\hline \multicolumn{7}{|l|}{ ORINA } \\
\hline $\mathrm{pH}$ & $6,8-7,7$ & 6,5 & 7,6 & 5,8 & 6,5 & 5,8 \\
\hline Calciuria mg.\% & 3,8 & 1,2 & 1,35 & 1,0 & indic. & indic. \\
\hline Fosfaturia $\mathrm{mg} / \mathrm{kg} / \mathrm{d}$ & 42 & 27 & 15,6 & & & \\
\hline PESO kg. & 10,0 & 10,2 & & & & 11,3 \\
\hline TALLA $\mathrm{cm}$. & 76 & 79 & & & & 80 \\
\hline $\mathrm{EDAD}$ & $8 \mathrm{~m} \cdot 10 \mathrm{~d}$ & $3^{\mathrm{a}} 3 \mathrm{~m} .21 \mathrm{~d}$. & & & & $3^{\text {a }} 5 \mathrm{~m} .6 \mathrm{~d}$. \\
\hline
\end{tabular}


neas de calcificación provisoria distal de fémures y proximal de tibias, ensanchamiento epifisiario; corticales no atrólicas y trama ósea de aspecto reticular.

Laboratorio: Sangre: Calcio 9,3; Fósforo $2,8 \mathrm{mg} \%$. Fosfatasa alcalina 13,2 U. B. En orina el sedimento es normal, no hay proteinuria ni glicosuria. La concentración máxima urinaria es de 560 miliosmoles por litro y la aminoaciduria es normal. La prueba de acidilicación urinaria corta con cloruro de amonio mostró buena acidificación con $\mathrm{pH}$ que bajó de 6,4 a 4,75 y aumento de excreción neta de $\mathrm{H}+$ de 67,9 a $159,1 \mathrm{uEq} / \mathrm{min}$./ $1.73 \mathrm{~m} 2$.

Se hace diagnóstico de raquitismo hipofosfatémico familiar y se trata con Fósforo Sandoz, M.R. 75 mg. 2 veces al día. Lleva cinco meses de control.

\section{COMENTARIO}

Los tres casos presentados corresponden a raquitismos refractarios a las dosis terapéuticas habituales de vitamina $D$, pero las características clínicas, de laboratorio y la evolución con el tratamiento empleado configuran cuadros de distinta etiología hasta donde el estudio realizado permite afirmarlo.

En ninguno de los 3 casos hubo antecedentes de uso de fenobarbital u otro anticonvulsivante, de hepatitis u otra enfermedad hepática que hubiera influido sobre la hidroxilación de la vitamina $\mathrm{D}$ en el hígado (6) (7) (8) (9).

Caso 1. Corresponde a Sindrome de Fanconi que evolucionó sin glicosuria.

Cuando falta la hormona antiraquítica, por carencia primaria o secundaria, las células del epitelio intestinal no pueden sintetizar la proteína transportadora del calcio, lo que conducc a déficit de absorción e hipocalcemia. La hipocalcemia estimula la parathormona y el hiperparatiroidismo secundario puede provocar alteración funcional del túbulo proximal del riñón, con aminoaciduria, acidosis tubular proximal, fosfaturia y glicosuria, o, dicho en otros términos el hiperparatiroidismo secundario puede provocar un sindrome de Fanconi (10). No se ha aclarado por qué, en algunos de estos casos, la alteración funcional del túbulo no compromete la reabsorción de glucosa y no hay glicosuria (11).

El tratamiento sintomático logró mejoría clínica y radiológica del raquitismo y desaparición de la acidosis tubular proximal. Los antecedentes permiten afimar que no es un trastorno familiar, tampoco se encontraron causas de sindrome de Fanconi adquirido como cistinosis, intoxicación con metales pesados o tetraciclinas vencidas.

Caso 2.- El análisis de conjunto del cuadro clínico y especialmente la evolución con el tratamiento efectuado orienta hacia una alteración de la normal producción de 1-25 dihidroxivitamina $\mathrm{D}$, aun cuando no se hizo dosificación del metabolito activo. Corresponde a las formas clinicas conocidas como "Raquitismo vitamina D dependiente", que se produce por deficiencia genética de la hidroxilasa renal y que ceden a la administración de dosis fisiológicas de hormona antiraquítica. Como la deficiencia no es absolu$\mathrm{ta}$, estas formas ceden también cuando se aumenta la cantidad de substrato para la hidroxilación renal. Con dosis elevadas, variables, de vitamina D se logra la síntesis de la cantidad necesaria de hormona antiraquítica que es lo que probablemente alcanzamos en esta paciente con las dosis de 200.000 unidades diarias y no logramos con dosis menores. La enfermedad es hereditaria de tipo autosómico recesivo (4).

Por ser el fósforo un agente mineralizador que impulsa el calcio plasmático al hueso (1) su administración puede tener efectos negativos cuando está alterada la absorción intestinal de calcio por falta de hormona antiraquítica u otra causa. El fósforo, en estos casos, intensifica la hipocalcemia y el hiperparatiroidismo secundario. Así se explica el resultado contraproducente que se observó en nuestra paciente cuando recibió fósforo solo y que no se modificó con la adición de calcio por vía oral.

Caso 3. Evidentemente se trata de un trastorno familiar. Hay dos generaciones seguidas comprometidas. El trastorno parece circunscribirse al metabolismo del fósforo sin función tubular comprometida. Tenemos suficientes elementos para concluir que se trata de una hipofosfatemia familiar.

La hipofosfatemia familiar es la enfermedad hereditaria dominante ligada al cromosoma $X(13)$ (12) que antigüamente se describía confundida con el raquitismo por insuficiencia de 25 hidroxicalciferol-1- hidroxilasa o raquitismo vitamino dependiente. La diferencia está no sólo en la forma de trasmisión hereditaria sino en su etiopatogenia. La hipofosfatemia familiar es provocada por alteración de los mecanismos de 
transporte transepitelial del fósforo, lo que impide la reabsorción tubular de este elemento y provoca fosfaturia e hipofosfemia sin carencia de hormona antiraquítica. En ocasiones puede acompañarse de una alteración igual en la célula intestinal dificultando además, la absorción del fósforo a ese nivel. Esto no se ha investigado en nuestra caso.

La administración de fósforo en nuestra paciente ha dado resultados favorables en cuanto a mejorar la fosfatemia.

Aún no se ha realizado estudio radiológico.

\section{RESUMEN}

Se presentan tres casos de raquitismo refractario a la vitamina $D$. Uno de ellos es un raquitismo con sindrome de Fanconi sin glicosuria, de etiología no precisada. Otro parece corresponder a raquitismo Vitamino Dependiente o seudocarencial y el tercero se debe a hipofosfatemia familiar.

Se comentan la etiopatogenia de estos tipos de raquitismo y la indicación terapéutica en cada uno de ellos.

\section{SUMMARY}

Three cases of refractory rickets to vitamin $D$ are presented. One of them was associated with Fanconi's syndrome of unknown etiology without glycosuria.

An other one seems to correspond with a vitamin dependent or pseudodeficient rickets.

The third case is due to a familial hypophosphatemia.

Etiopathogeny of these types of rickets and therapy in each of them are commented.

NOTA: Desde que esta comunicación fue terminada hasta la fecha se han estudiado otros dos casos de hipofosfatemia familiar. Uno de ellos es el hermano menor de P.Z.C. (caso 3) y el otro una niña de 4 años de edad.

Agradecimientos: Agradecemos la colaboración del Dr. Jorge Litvak en el manejo del primer caso, de las señoritas Gilda Borie y Miriam Cortés que nos ayudaron con la realización de todos los controles de laboratorio y del Laboratorio Sandoz que gentilmente nos proporcionó el fósforo para el tratamiento.

\section{BIBLIOGRAFIA}

1.- Torres-Goitía J., Fernández, E., Vallejos, E., Radrigán, M. E.: Raquitismo. Revista Chilena de Pediatría. Pub. en este mismo número.
2,- De Luca, H. F.: Vitamina D. 1973. The Amr. J. of Med. 57: 1-12, 1974.

3.- Norman, A. W.: 1-25 Dihydroxyvitamin D: A Kidney producer Steroid Hormone Essential to Calcium Homeostasis. The Amer. J. of Med. 57: 21-27, 1974.

4.- Fraser, D., Kooh, S. W., Kind, H. P., Holick, M. F., Tanaka, Y., and DeLuca, H.F.: Pathogenesis of Hereditary vitamina-D-Dependent Rickets. An Inborn Error of Vitamin D Metabolism Involving Defective Conversion of 25-Hydroxyvitamin D to 1-alfa, 25 Dihydroxyvitamin D. New. Engl. J. Med. 289: 817-822, 1973.

5.- Fanconi, G.: Osteopatías de origen genético. Triángulo 12: 129-138. 1974.

6.- Stamp, T. C. B.: Effects of Long-term Anticonvulsivant therapy on Calcium and Vitamin D Metabolism. Proc. R. Soc. Ned. 67: 64-68. 1974.

7.- Matsuda, I., Takekoshi, Y., Shida, N., Fuijieda, K., Nagai, B., Arashima, S., Anakura, M. and oka, Y.: Renal tubular acidosis and skeletal demineralization in patients on long-term anticonvulsant therapy. The Journal of Pediatrics. 87: 202-205. 1975 .

8.- Chesney, R. W. and Harrison, H. E.: Fanconi syndrome following bowel surgery and hepatitis reversed by 25 hydroxicholecalsifeol. J. Pedia. 86: $857-861,1975$.

9.- Latorre, H., Kenny, F.: High Dosage Intravenous calcium therapy dor osteoporosis and osteomala. sia in anticonvulsant tehrapy with hypomovilization. Pediatrics. 53: 100-104, 1974.

10.- Guignard, J. P. and Torrado, A.: Proximal renal tubular acidosis in vitamin $\mathrm{D}$ deficiency Rickets. Acta Paediatr. Scand. 62: 543-546. 1973.

11.- Fraser, D., Kooh, S. W. Scriber, C. R.: Hyperparathyroidism as the cause of Hyperaminoaciduria and phosphaturia in human vitamin D deficiency. Pediat. Res. 1: 425-231. 1967.

12.- Scriver, C. R., Glorieus, F. H., Reade, T. and Tenenhoise, H.: Familial hypophosphatemic (Xlinked) Rickets. Pediatría XIV. Actas del XIV Congreso Internacional de Pediatría. 3-9 de octubre de 1974. Buenos Aires. Ed. Médica Panamericana. 1974. T. 10. pp. 103-105.

13.- Scriver, C. R.: Familial hypophosphatemia. The dilema of treatment. New. Engl. J. Med. 289: 531-532, 1973. 